\section{Studies of an Electron Transport Particle from Candida utilis ${ }^{2}$}

We previously isolated an electron transport particle (ETP) from Saccharomyces cerevisiae and showed that oxidation of DPNH by the preparations is not inhibited by seconal or rotenone $(1,2)$ in contrast to heart muscle preparations in which DPNH oxidation is highly sensitive to the inhibitors (3). In addition, the preparations contain only flavin adenine dinucleotide (FAD), and the mammalian preparations contain both FAD and flavin mononucleotide (FMN) $(1,4)$. Finally, the soluble DPNH dehydrogenase isolated from the yeast ETP does not contain iron and labile sulfide groups $(5,6)$ as does the similarly prepared soluble DPNH dehydrogenase from beef heart $(6,7)$.

The present communication describes the properties of an ETP from another yeast, Candida utilis (Torulopsis utilis), and presents data showing that the preparation is seconal- and rotenonesensitive and contains FMN in addition to FAD, thus resembling the mammalian preparation rather than the ETP of S. cerevisiae. Furthermore, the ETP from $C$. utilis contains coenzyme $Q_{7}$ rather than $\mathrm{Q}_{6}$ (S. cerevisiae) or $\mathrm{Q}_{10}$ (heart muscle), and in much lower amounts than in the preparations of ETP from heart or S. cerevisiae.

Electron transport particles from $S$. cerevisiae and $C$. utilis were prepared as described previously by Mahler et al. (2). Assays for cnzymic activity were performed either spectrophotometrically or by use of an oxygen polarograph as described previously $(1,8)$. Protein, iron, copper, coenzyme $\mathrm{Q}$, cytochromes, flavin, and labile sulfide were determined by methods described elsewhere $(1,0)$.

Preparations of ETP from C. utilis catalyzed the oxidation of 1.5-1.8 $\mu$ moles of DPNH and approximately $0.5 \mu$ mole of succinale per minute per milligram of enzyme protein and did not consistently show the marked stimulation of activity when cytochrome $c$ was added to the assays that is shown by preparations of ETP from $S$. cerevisiae $(1,2)$. As shown in Table 1, preparations of ETP (C. utilis) of the highest activity contain cytochromes $a, a_{3}, b, c$, and $c_{1}$, nonheme iron, labile sulfide, copper, flavin, coenzyme $Q$, and approximately $30 \%$ lipid (dry weight). The preparations of ETP from C. utilis differ in composition from those of $S$. cerevisiae in that they contain lower amounts of flavin and coenzyne $Q$. Further studies of the flavins by chromatographic procedures and

1 This work was supported in part by grants H-5457 and GM-12176, and training grant 5T01HD-00005 from the National Institutes of Health. by studies of reactivation of specific apoenzymes performed as described previously (4) demonstrated that FMN and FAD were present in the C. utilis ETP in nearly equal amounts in contrast to an ETP from $S$. cerevisiae which has been shown to contain only FAD (1). In other experiments, coenzyme $Q$ extracted both from intact cells and from preparations of ETP of $C$. ulitis was studied by thin-layer chromatography on silica gel in a solvent system of $1 \%$ ether in benzene, and the preparation was identified as coenzyme $Q_{7}$, thus differing from preparations from $S$. cerevisiae and heart muscle which contain coenzyme $Q_{6}$ and coenzyme $Q_{10}$, respectively. No coenzyme $Q_{9}$ was found in the $C$. utilis preparations as previously described by Crane (10), but this may be due to the small amount of coenzyme $Q_{y}$ which was reported to be present. In preparations of ETP from C. utilis of lower activity (1-1.2 $\mu$ moles DPNH oxidized per minute per milligram protein), the nonheme iron and labile sulfide content was nearly double the concentrations found in the more active preparations.

Preparations of ETP from $C$. utilis were inhibited over 95\% (succinic and DPNH oxidase activities) by antimycin $\mathrm{A}(1 \mu \mathrm{g} / \mathrm{ml})$ as are ETP preparations from heart (11) and $S$. cerevisiae (1). The DPNH oxidase and DPNH coenzyme $Q$ reductase activities of preparations of $C$. utilis ETP were inhibited 90 and $75 \%$, respectively, by seconal ( $2 \mathrm{~mm})$, and by rotenone $(2 \mu \mathrm{M})$, compounds which inhibit preparations of heart ETP (3) but not ETP from $S$. cerevisiae (2) at low concentrations. In addition, seconal (4 mm) inhibited the succinic oxidase and succinic cytochrome $c$ reductase activities of the $C$. utilis ETP $80-90 \%$ (the corresponding activities of heart ETP are not inhibited); however, rotenone $(10 \mu \mathrm{M})$ did not inhibit the succinic oxidase activity. The inhibition of succinic oxidase activity by seconal was usually not immediate, and increased to maximal values progressively over a 2 - to 3 -minute period of incubation at $38^{\circ}$. Furthermore, the inhibition was present only when the enzyme was assayed in phosphate buffer. When assays were performed in Tris buffer or at temperatures under $30^{\circ}$, no inhibition of succinic oxidase activity by seconal was observed.

The ETP from both $S$. cerevisiae and $C$. utilis have been examined by low-temperature EPR spectroscopy. Both preparations show the copper signal of cytochrome oxidase in the oxidized form and the " $g=1.94$ " resonance of nonheme iron proteins on reduction, either enzymically with DPNH or succinate or chemically with dithionite (12). As shown in Fig. 1, the main qualitative differences in the EPR spectra of the reduced 
TABLE I

Comparison of the Composition ${ }^{a}$ of ETP from C. utilis AND S. cerevisiae $^{b}$

\begin{tabular}{|c|c|c|c|c|c|c|c|c|c|}
\hline \multirow{2}{*}{ Preparation } & \multirow{2}{*}{$\begin{array}{l}\text { Total } \\
\text { flavin }\end{array}$} & \multirow{2}{*}{$\underset{Q}{\text { Coenzyme }}$} & \multirow{2}{*}{$\underset{\text { iron }}{\text { Nonheme }}$} & \multirow{2}{*}{$\underset{\mathrm{S}}{\text { Labile }}$} & \multirow{2}{*}{ Copper } & \multicolumn{4}{|c|}{ Cytochromes } \\
\hline & & & & & & $c+c_{1}$ & $b$ & $a+a_{3}$ & Total \\
\hline ETP of C. utilis & 0.33 & 0.27 & 2.0 & 2.4 & 1.5 & 0.39 & 0.46 & 0.99 & 1.8 \\
\hline $\mathrm{ETP}^{b}$ of $S$. cerevisiae & 0.95 & 1.6 & 2.6 & - & 1.0 & 0.61 & 0.77 & 0.78 & 2.2 \\
\hline
\end{tabular}

"All values are the average of data for three or more preparations and are expressed as $\mathrm{m} \mu \mathrm{moles} / \mathrm{mg}$ of protein except as noted in the Table.

${ }^{b}$ Values previously reported by Mackler et al. (9).

ETP from the two organisms is the location of the shoulder on the principal high-field resonance. In $S$. cerevisiae the shoulder appears unusual and may represent the middle component of an anisotropic g-tensor. Both DPNH and succinate (though to a lesser extent) elicit this signal, which suggests that it is related to a component of the enzyme common to the pathways of electron transport for both substrates. With C. utilis, however, the shoulder appears to be due to a second species of iron associated with the succinic dehydrogenase portion of the ETP, for whereas reduction with DPNH produces the whole signal, succinate gives only that component responsible for the shoulder.

In summary, ETP prepared from C. utilis appears to differ from ETP from $S$. cerevisiae and resembles heart muscle ETP by containing a second nonheme iron component which is reduced by DPNH but not by succinate, and which may therefore be associated with the DPNH dehydrogenase portion of the system as suggested by the EPR studies described above. In addition, the $C$. utilis preparations contain FMN in addition to FAI, and the DPNH oxidase activity is inhibited by low concentrations of seconal and rotenone. The similarity in structure of the heart muscle preparations and the ElP from C. utilis suggests the possibility that the sensitivity of DPNH oxidase activity to seconal and rotenone and the substrate level phosphorylation associated with DPNH oxidation in heart muscle may be related to the FMN component and/or to the nonheme iron component which are not present in the ETP of S. cerevisiae. Finally, the ETP from C. utilis differs from similar preparations from heart in that the succinic oxidase activity of the preparations under certain conditions is highly sensitive to inhibition by seconal.

\section{ACKNOWLEDGMENTS}

The authors wish to thank Standard Brands, Inc. for the generous supply of Fleischmann's yeast, Ayerst Labs. for the antimycin A, Dr. O.
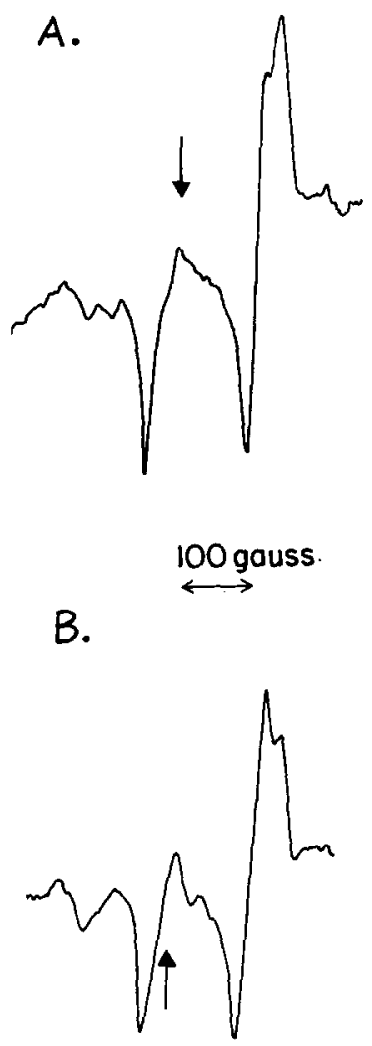

FIG. 1. Electron paramagnetic resonance spectra of ETP from $S$. cerevisiae (A) and C. utilis (B) reduced with excess DPNH. Protein concentration was $20 \mathrm{mg} / \mathrm{ml}$. Modulation amplitude, 12 gauss; microwave power, $27 \mathrm{~mW}$; sean speed, 400 gauss/minute; time constant, 1 second; Temperature $68^{\circ} \mathrm{K}$; Varian V-4500, X Band spectrometer. The vertical arrows denote $g=2$; the magnetic field increases from left to right.

Isler for coenzyme $Q$ and $Q_{3}$, Dr. H. J. Phaff for providing the culture of $C$. utilis, and Mr. Richard Grace for his valuable technical assistance. 


\section{REFERENCES}

1. Mackler, B., Collipp, P. J., Duncan, H. M., RaO, N. A., and Huennekens, F. M., $J$. Biol. Chem. 237, 2968 (1962).

2. MAHLER, H. R., MACKLER, B., GRANDChaMP, S., AND Slonimski, P. P., Biochemistry 3, 668 (1964).

3. Cowger, M. L., LABbe, R. F., and Mackler, B., Arch. Biochem. Biophys. 96, 583 (1962).

4. Rao, N. A., Telton, S. P., Hugnnekens, F. M., and Mackter, B., J. Biol. Chem. 238, 449 (1963).

5. Duncan, H. M., and Mackler, B., Biochemistry 5, 45 (1966).

6. MACKLeR, B., in "Non-Heme Iron Proteins: Role in Energy Conversion" (A. San Pietro, ed.), p. 421. Antioch Press, Yellow Springs, Ohio (1965).

7. MACKLeR, B., Biochim. Biophys. Acta 50, 141 (1961).

8. Sharp, C. W., Doctoral dissertation, Indiana University (1966).

9. Mackler, B., Douglas, H. C., Will, S., Hawthorne, D. C., and Mahler, H. R., Biochemistry 4, 2016 (1965).

10. Crane, F. L., Ciba Found. Symp. Quinones in Electron Transport p. 414. Little, Brown, Boston (1961).
11. Mackler, B., AND Green, D. E., Biochim. Biophys. Acta 21, 6 (1956).

12. Beinert, H., Heinin, W., and Palmer, G., Brookhaven Symp. Biol. 15, 229 (1962).

Charles W. Sharp ${ }^{2}$

BrUCE MACKLER ${ }^{3}$

H. C. Douglas

Departments of Pediatrics,

Microbiology, and Genetics

University of Washington

Seattle, Washington

Graham Palmer ${ }^{3}$

Biophysics Research Division

University of Michigan

Ann Arbor, Michigan

S. P. Felton

Children's Orthopedic Hospital

Seattle, Washington

Received November 3, 1967

${ }_{2}$ Postdoctoral Research Trainee supported by training grant 5T01-HD-00005 from the National Institutes of Health.

${ }^{3}$ This work was performed during the tenure of career development awards 2K3-HD-1128 (B.M.) and GM-K3-31,213 (G.P.) from the National Institutes of Health. 